Инна Хатипова Академия музыки, театра и изобразительных искусств, г. Кишинев, Республика Молдова ORCID ID 0000-0003-2745-7978 DOI 10.24139/2312-5993/2020.05-06/281-292

\title{
ПРЕЛЮДИИ ДЛЯ ФОРТЕПИАНО КОМПОЗИТОРОВ РЕСПУБЛИКИ МОЛДОВА В РЕПЕРТУАРЕ СТУДЕНТОВ-ПИАНИСТОВ АКАДЕМИИ МУЗЫКИ, ТЕАТРА И ИЗОБРАЗИТЕЛЬНЫХ ИСКУССТВ
}

В настоящей статье автор обращается к жанру прелюдии - одному из самых популярных в фортепианной музыке. Жанр прелюдии нашел широкое распространение и в творчестве композиторов Республики Молдова. Цель статьи - рассмотрение с исполнительской точки зрения прелюдий для фортепиано, написанных отечественными авторами и включенных в педагогический репертуар студентовпианистов кафедры специального фортепиано Академии музыки, театра и изобразительных искусств. Автор анализирует форму этих сочинений, черты стиля, особенности драматургии, композиторского языка. Статья содержит многочисленные исполнительские и педагогические рекомендации для молодых пианистов. Делается вывод о роли данных пьес в оптимизации процесса профрессионального образования и воспитания студентов.

Ключевые слова: фортепианная музыка, жанр прелюдии, музыкальная фрорма, фортепианная фактура, молдавский фольклор, исполнительский анализ, концертно-педагогический репертуар, композиторы Республики Молдова.

Постановка проблемы. Жанр фортепианной прелюдии неизменно привлекал внимание композиторов Республики Молдова. Наряду с другими инструментальными миниатюрами, прелюдии для фортепиано отечественных авторов являются благодатным музыкальным материалом для учебного процесса в учебных заведениях разного уровня.

Анализ последних научных публикаций. Фортепианные прелюдии Георгия Няги, Владимира Ротару, Семена Лунгула, Константина Руснака, Алексея и Мариана Стырчи, Виталия Сечкина эскизно затрагиваются в монографических исследованиях молдавских музыковедов Е. Клетинича (Клетинич, 1983), А. Мирошникова (Мирошников, 1973) и Е.Гупаловой (Гупалова, 2008). Подробный исполнительский анализ прелюдий вышеуказанных композиторов в настоящей статье производится впервые.

Цель статьи - охарактеризовать те фортепианные прелюдии, которые созданы молдавскими композиторами и используются в педагогическом репертуаре пианистов Академии музыки, театра и 
изобразительных искусств. Для этого выполнен анализ соответствующих прелюдий с указанием пианистических трудностей, обусловливающих возможность их привлечения при подготовке музыкантов-исполнителей.

Методология исследования. В процессе исследования образцов жанра фортепианной прелюдии в творчестве композиторов Республики Молдова использовался комплекс методов современного искусствоведения, направленных на теоретическое осмысление поставленной проблемы. На эмпирическом уровне исследования был произведен отбор прелюдий, входящих в концертный и педагогический репертуар студентов-пианистов Академии музыки, театра и изобразительных искусств Республики Молдова. На теоретическом уровне использовались общенаучные методы: анализ и синтез, индукция и дедукция, сравнение и др.

Изложение основного материала. Жанр фортепианной прелюдии неизменно привлекал внимание и находился в сфере творческих интересов отечественных композиторов. Первые профессиональные образцы данного жанра в молдавской фортепианной литературе создал Штефан Няга. Две его фортепианные прелюдии, написанные в 40-е годы XX века, по праву считаются одними из первых удачных примеров национально характерного решения жанра. Помимо этого, прелюдии для фортепиано можно найти в композиторском творчестве Г. Няги, В. Ротару, К. Руснака, М. Стырчи и многих других авторов. Проанализируем наиболее показательные из них.

Две прелюдии для фортепиано, чрезвычайно популярные в педагогической практике музыкальных учебных заведений Республики Молдова, принадлежат перу А. Стырчи. Они контрастны между собой: первая (As-dur) - светлая, лиричная, вторую (es-moll) отличают драматизм и бурный, взволнованный характер. Прелюдия As-dur для фортепиано А. Стырчи, созданная в 1946 году, написана в однотемной простой трехчастной форме $\left(a-a_{1}-a\right)$. Основная ее тема очень светлая, певучая, лирически наполненная. Мелодия повествовательного характера (в верхнем голосе партии правой руки) звучит на фоне аккордов хорального склада в аккомпанементе. В их выразительности важная роль принадлежит альтерационным изменениям ступеней (понижение VI, II, повышение IV ступеней), что придает музыке национально определенный характер. Поэтому исполнителю нужно не только добиться теплого, певучего звука и хорошего legato в мелодии, но и прослушать и оттенить наиболее выразительные гармонии в аккомпанементе.

Средняя часть (Più mosso, т. 9) начинается очень тихо, затаенно, словно издалека. Характер музыки постепенно меняется, становясь все 
более взволнованным и драматичным. Секвенционное развитие мелодии сопряжено с подъемом во все более высокие регистры.

В репризе основная тема Прелюдии обновляется за счет перемещения в более высокий, «колокольчиковый» регистр (авторская ремарка quasi campanelli), изменения фактуры (мелодия звучит в обрамлении шестнадцатых).

Прелюдия es-moll воплощает бурный, страстный, драматичный порыв. Интонационно она близка ранним опусам А. Скрябина. Характерными особенностями данного сочинения является очень насыщенная динамика (почти постоянное $f$ и ff) и непрерывная взволнованная триольная пульсация.

Прелюдия написана в простой двухчастной форме $\left(\mathrm{a}-\mathrm{a}_{1}\right)$. В общем фактурном комплексе, где важная роль принадлежит октавноаккордовому складу и триольному ритмическому рисунку сопровождения, мелодический голос должен быть ясно проинтонирован, движение баса представлять собой логически развитую линию.

Исполнение данной Прелюдии может быть рекомендовано не только на различных курсах АМТИИ, но и в старших классах музыкальных лицеев. Работа над этим сочинением, в соответствии с его романтической направленностью, может явиться подготовительным этапом для последующего исполнения сочинений западноевропейских композиторовромантиков, а также А. Скрябина и С. Рахманинова.

Г. Нягой написана для фортепиано Прелюдия es-moll. Созданная в годы учебы в консерватории, она несет на себе следы влияния творчества композиторов-импрессионистов, заставляет вспомнить прелюдии К. Дебюсси Паруса, Затонувший собор и многие другие. Об этом свидетельствуют характерные для нее красочные колористические эффекты, богатство гармонических наслоений, частые и неожиданные смены тональностей. В то же время в произведении Г. Няги постоянно улавливаются типичные для молдавских ладов интонационные обороты (с участием II пониженной и IV повышенной ступеней). Это сочетание придает облику Прелюдии неповторимое очарование и своеобразие.

По форме Прелюдия одночастна и вся от начала до конца (на протяжении шестнадцати тактов) выдержана в одной фактуре: арпеджированные аккорды на фоне мощных колокольных басов. Однако согласно гармоническому и тональному развитию, в структуре пьесы можно выделить три раздела (8т. +4т. +4т.). 
В исполнении основной темы пианист должен следить за тем, чтобы в арпеджированных аккордах, как органного типа, так и струящихся, арфообразных гармонических фигурациях в высоком регистре, постоянно преобладал верхний мелодический голос правой руки. Верхние тоны аккордов образуют при этом связную певучую мелодическую линию.

Прелюдия cis-moll C. Лунгула, написанная в 1980-е годы (издана в 1988 г. в сборнике под редакцией В.Левинзона и С. Коваленко) (Коваленко, Левинзон, 1988), продолжает традицию обращения молдавских авторов к данному музыкальному жанру. С. Лунгул в своей cismoll'ной Прелюдии не ставит перед собой задачи создания музыки в молдавском национальном духе. Его пьеса по своему музыкальному языку является произведением универсального, общеевропейского, национально нейтрального типа. Прелюдия, в которой просматриваются черты трехчастной композиции $\left(a-a_{1}-a\right)$, носит лирический характер, в ней присутствует некоторый оттенок таинственности и мечтательности.

Пьеса начинается с небольшого двухтактового вступления на $p p$, очень спокойно, задумчиво, Росо misterioso.

Основная тема (т. 3) представляет собой напевную, повествовательную, пластичную линию, скрытую в аккордовой фактуре среднего голоса. Тема опирается на глубокие органные басы сіs в октавном изложении. Они поддерживают атмосферу, созданную во вступлении.

Мелодическая линия среднего эпизода строится на интонациях основной темы, развивая ее в каноническом изложении. Небольшое ritenuto в т. 27, помогая хорошо «дослушать» dis в партии левой руки, подводит к сокращенной репризе. В ней сохраняется музыкальный материал первой части, однако, в отличие от первого изложения темы, где динамика усиливается, здесь, наоборот, громкость постепенно стихает. Кроме этого, основная тема представлена не полностью, в репризе звучит только начальная интонация. Прелюдия заканчивается очень спокойно, на рр.

В заключение отметим, что гамма оттенков различных настроений в этой прелюдии подчеркивает пластичность мелодического образа, что существенно облегчает исполнителю решение задачи цельности и единства формы.

Еще одним ярким примером данного жанра в творчестве отечественных авторов является Прелюдия К. Руснака. Художественные установки К. Руснака определяются гармоничным сочетанием двух основных сторон его профессиональной музыкальной деятельности: композитора и музыковеда-фольклориста. Собирание, запись и изучение 
образцов молдавского фольклора наложило отпечаток на композиторский стиль К. Руснака. Его первые опыты связаны с созданием произведений для оркестра народных инструментов на основе обработок народных мелодий. К настоящему времени композитором сделано свыше сорока обработок народных песен и мелодий для оркестра молдавской народной музыки, написано большое количество песен, романсов, инструментальных пьес. Музыковед Г.Пирогова отмечает, что «... творческом багаже К. Руснака, наряду с обработками, - множество оригинальных произведений, в которых нашли опосредованное выражение неповторимый дух молдавского фольклора, характерные черты его интонационно-ритмического словаря» (Березовикова, 1982, с. 75). Индивидуальный стиль К. Руснака отличают в целом тонкое мелодическое чутье, полифоничность музыкальной ткани, вариантность развития музыкального материала. Данные черты нашли отражение и в его Прелюдии для фортепиано. Эта пьеса обрела большую известность в местной пианистической среде, она часто исполняется на академических зачетах и экзаменах студентами фортепианной кафедры АМТИИ.

Своеобразие облика миниатюры определяется оригинальным сочетанием тонких импрессионистических красок в звукописи и яркой национальной характерности музыкального тематизма.

Пьеса написана под влиянием стилистики дойны. Композитор сумел выразить характерное для дойны импровизационное начало, которое проявляется в использовании принципа «..многократного, не регламентированного жесткими нормами повторения единиц музыкальной формы (мотива, фразы, куплета). Раскованность фольклорного интонирования весьма органично обнаруживает себя также в свободном варьировании, /../ где отражается богатая игра индивидуальных оттенков основного образа» (Бирюков, 1984, с. 138). В Прелюдии К. Руснак проявил себя как искусный мастер вариантного преобразования материала: каждый из основных разделов прелюдии строится на всевозможных вариантах основной темы, трансформирующих ее мелодию, ритмику, фактуру.

Прелюдия монотематична, в ее структуре можно выделить три раздела $\left(a-a_{1}-a\right)$ : экспозиционный, развивающий и заключительный, дополненный кодой.

В связи с характерной для Прелюдии многоплановой фактурой с выдержанными тонами, с наслоениями по-разному окрашенных пластов на одно из первых мест при ее исполнении выступает внимание к педали. 
Общие педальные указания в пьесе даны самим автором, а детализация тонкостей уже зависит от мастерства и уровня техники исполнителя. При всех сложных фактурных напластованиях необходимо стремиться к ясности звучания в противовес аморфной игре на одной общей педали, поэтому в сочинении возможно применение полупедали, вибрирующей педали, одновременного использования правой и левой педали.

Важную роль в интерпретации Прелюдии играет также звуковое разнообразие, многокрасочность. Задача пианиста - искусно «инструментовать» каждую фактурную линию или пласт, а затем выявить их звуковые и тембровые соотношения.

В некотором смысле с прелюдией К. Руснака перекликается Прелюдия a-moll B. Ротару. В Прелюдии a-moll начальным обозначением (Andante doloroso e molto rubato) автор однозначно направляет музыкальное мышление исполнителя, предлагая импровизационную манеру игры, свободу и раскрепощенность творческого воображения.

Произведение отличается явно выраженной жанровой образностью, полностью погружая слушателя В поэтическую атмосферу дойны. В сочинении находят отражение ее свободный стиль и характер глубокой боли, грусти и тоски. Поэтический облик молдавской дойны композитор облек в простую трехчастную монотематическую форму с кодой $\left(a-a_{1}-a\right)$.

Интересно отметить, что в первоначальном варианте, в рукописи, пьеса называлась Preludiu vocal. Для исполнителей этот факт имеет большое значение, так как выявляет вокальную природу линии верхнего голоса и фактуры в целом. Другими словами, в исполнении Прелюдии кантиленность должна проявляться во всех слоях ее фактуры: певучие басы, поющие фигурации сопровождения и текучая напевная мелодия. Соответственно, штрих legato sempre должен господствовать над всеми остальными штрихами.

В первом вступительном такте мягкие напевные триоли готовят почву для появления верхнего мелодического голоса. Основная тема Прелюдии сразу вызывает в памяти медленные молдавские дойны со свойственными им особенностями фольклорного стиля parlando rubato.

В мелодическую линию темы удачно вплетены многочисленные мелизмы: трели, форшлаги, морденты; нисходящие секундовые «вздохи» создают элегическое настроение, характерные для дойн длительные остановки в конце фраз выражают задумчивость, усталость и печаль.

Медленное развертывание мелодии сопровождается непрерывным триольным движением в среднем голосе. 
Работая над этой проникновенной лирической миниатюрой, студенты-пианисты могут теснее соприкоснуться с богатейшим художественным миром молдавской дойны, усовершенствовать навыки кантиленной игры, развить свою творческую исполнительскую фантазию.

Две прелюдии для фортепиано М. Стырча написал, возможно, по примеру своего отца-композитора А. Стырчи. Но если в прелюдиях А. Стырчи ощутимо воздействие творчества русских композиторов, особенно П.Чайковского и С. Рахманинова, то прелюдии М.Стырчи отличают использование средств современного музыкального языка, насыщенность острыми ритмами и диссонантными гармониями. Прелюдии часто исполняются вместе - так, как они опубликованы в сборнике Piese pentru pian (Коваленко, Левинзон, 1988).

Вполне вероятно, что они и задуманы композитором как небольшой цикл, будучи соединенными друг с другом по принципу темпового и образного контраста. Тем не менее, каждая из прелюдий имеет собственный индивидуальный облик и стилевые характеристики.

Первая прелюдия монотематична, в ней экспонируется и претерпевает дальнейшие метаморфозы первоначальный юмористический скерцозный образ с чертами гротесковости. Основной тематический материал включает два элемента: в ответ на задорную, озорную реплику несколько залихватского характера звучит угловатый, резкий мотив во втором такте.

Интересно, что синкопированный ритм озорного мотива является основной ритмической ячейкой всей миниатюры и придает пьесе характер каприччио, указанный в авторской ремарке (Scherzando capriccioso). Также в прелюдии обращает на себя внимание предельный лаконизм фактуры: во многих тактах тематический материал излагается в партии одной руки без гармонического сопровождения, мелодического контрапункта или каких-либо иных фактурных компонентов.

Вторая прелюдия контрастирует с предыдущей по темпу и типу рисуемых художественных образов, что проявляется уже в начальном композиторском указании: Allegro con fuoco. Одним из отличительных качеств этой прелюдии является сочетание современной гармонической лексики и яркого молдавского фольклорного колорита. Влияние молдавской народной музыки ощущается и в интонационном строе сочинения, и в опоре на фольклорную жанровость.

Первая часть Прелюдии, написанной в простой трехчастной форме $(a-b-a),-$ это яркая зарисовка в стиле молдавского народного танца, 
стремительного, темпераментного, с характерной ритмикой. Средний раздел Прелюдиu, Molto meno mosso (т. 16), переносит слушателя в лирическую сферу образов. Сама ремарка rubato сарriccio отчетливо указывает на импровизационность, свободную манеру исполнения. Жалобные секундовые интонации, прихотливый ритмический рисунок мелодии, характерная мелизматика, свободное мотивно-вариантное развертывание материала напоминают мелодические обороты молдавской дойны с характерными чертами стиля parlando rubato. В то же время в звучании среднего эпизода Прелюдии ощущается влияние джазовых интонаций, как следствие увлечения композитора искусством джазовой импровизации. Третья часть - реприза - (Tempo I) в целом повторяет материал первого раздела.

Молодых исполнителей республики Молдова неизменно привлекают в прелюдиях М. Стырчи современное звучание, контрастность образов в сочетании с лаконичностью формы и яркой национальной окрашенностью.

Жанр прелюдии также находился в спектре творческих интересов композитора Виталия Сечкина‥ Пять прелюдов-картин (Сечкин, 2014), созданные в последний, кишиневский, период творческого пути В. Сечкина, когда он стал членом Союза композиторов Молдавской ССР, характеризуют определенный этап творческой эволюции композитора, являясь итогом его поисков в области музыкального языка, жанров и форм фортепианной музыки. По словам самого автора, на написание этих фортепианных пьес его вдохновили живописные пейзажи Молдовы. Вполне вероятно, что Пять прелюдов-картин были задуманы как цикл, поскольку они соединены друг с другом принципом темпового и образного контраста. Тем не менее, каждая из миниатюр имеет собственный индивидуальный облик и стилевые характеристики. Автору

\footnotetext{
1 Виталий Васильевич Сечкин (1927, Харьков - 1988, Кишинев) - украинский композитор, пианист, педагог, музыкально-общественный деятель, Заслуженный артист Украины, профессор. В 1954 г. В. Сечкин окончил аспирантуру Московской консерватории по классу фортепиано Я. Зака. Он был блестящим пианистом, участником многих международных конкурсов и фестивалей, в том числе лауреатом (І-я премия) международного конкурса пианистов в Берлине (1951 г.).

Почти 30 лет (1972-1985) В. Сечкин проработал в Киевской консерватории, пройдя путь от преподавателя до заведующего кафедрой специального фортепиано, профессора и декана фортепианного факультета. Последние годы жизни (1985-1988) В. Сечкин был заведующим кафедрой специального фортепиано Молдавской Государственной консерватории им. Г. Музическу, передавая свои знания и опыт молодым музыкантам Молдовы.

Помимо исполнительской и преподавательской деятельности В. Сечкин занимался композиторским творчеством. Он был автором многих сочинений разных жанров - от миниатюр до фортепианного концерта. Особое отношение композитор испытывал к фортепианной музыке. Для фортепиано им написаны две сонаты, сюита Музыкальные картинки Чехословакии, вариации, три прелюдии, Думка, Праздничная поэма, три этюда-картины, Сюита для двух фортепиано.
} 
этой статьи посчастливилось быть первым слушателем и впоследствии первым после композитора исполнителем этих поэтичных фортепианных миниатюр. Обратимся к анализу данных пьес.

Прелюд-картина № 1 написан в однотемной сложной трехчастной форме $(A-B-A)$ в тональности f-moll. Основная его тема покоряет нежным, проникновенным характером музыки и мелодическим обаянием. Образный строй очень точно определяет авторская ремарка inaferando (ит. - неуловимо, чуть касаясь), впервые примененная русским композитором А. Скрябиным.

Пианисту в работе над этой пьесой основное внимание необходимо уделить исполнению мелодии: она должна быть хорошо проинтонирована, звучать ровно, плавно в звуковом отношении и, вместе с тем, гибко и пластично. Такое ее ведение будет соответствовать естественности и непринужденности развития музыкального материала, присущего этой фортепианной миниатюре.

Прелюд-картина № 2 представляет собой небольшое сочинение скерцозного характера. На это указывает и первоначальное обозначение автора - scherzando molto. Являясь произведением игривого, озорного характера, оно привлекает внимание светлым оптимистическим настроением, прихотливым ритмическим узором, легкостью и прозрачностью фактуры.

Пьеса написана в сложной трехчастной форме $(A-B-A)$. Основная тема первой части изобилует акцентами и острыми staccato. Ocновное внимание в работе над этим прелюдом необходимо уделить точному воспроизведению пунктирного ритмического рисунка в партии правой руки и штрихам: сочетанию legato, staccato и tenuto в партиях правой и левой руки, а также мелким лигам в мелодической линии.

Прелюд-картина № 3 носит название Над Днестром. Характерные для него красочные колористические эффекты, богатство гармонических наслоений, частые и неожиданные смены тональностей вызывают ассоциации с творчеством композиторов-импрессионистов. Образный строй этого прелюда отличается особой тонкостью, одухотворенностью и поэтичностью.

Пьеса написана в сложной трехчастной форме с динамической репризой $\left(A-B-A_{1}\right)$ в тональности a-moll. В фактурном строении прелюда просматриваются три плана: басовая триольная линия восьмых, альтовый голос, выполняющий функцию мелодического контрапункта и очень спокойная и выразительная мелодия, являющаяся основной темой 
сочинения. Она появляется в партии правой руки и звучит на фоне аккомпанирующего триольного движения восьмых в басовом регистре. Здесь к авторскому указанию dolce следует добавить также legato e molto cantabile.

От исполнителя требуется тщательное изучение тонального плана пьесы, так как частая смена тональностей играет важную роль в развитии темы, придавая музыке импровизационный характер.

Прелюд-картина № 4 называется Перед грозой. Пьеса представляет собой виртуозное сочинение романтического плана. Форма здесь сложная двухчастная $\left(A-A_{1}\right)$. Первая часть открывается основной темой, в выразительности которой большую роль играют трепетные взлетающие триольные пассажи шестнадцатыми, распределенные композитором между двумя руками. Пассажи вызывают ассоциации с сильными порывами ветра перед начинающейся грозой и должны быть сыграны molto animato e agitato.

Фактура второй темы и характер музыки близки известной Прелюдии op. 28 № 4 Ф.Шопена. Серьезной работы потребует от пианиста исполнение партии аккомпанемента: как строго одновременное звукоизвлечение в аккордах, так и molto legato, призванное создать впечатление непрерывного их звучания без помощи правой педали.

В начале прелюда отсутствует авторское обозначение темпа. Не следует играть пьесу чересчур быстро: вся фактура должна быть хорошо проинтонирована. Предполагаемый темп $d=96$.

Прелюд-картина № 5 снабжен композитором подзаголовком Памяти павших. Пьеса написана в простой двухчастной форме $\left(a-a_{1}\right)$ с кодой и вся от начала до конца выдержана в одной фактуре: аккорды, выписанные половинными нотами, на фоне остинатной триольной фигурации восьмыми в басовом регистре. Основная тема, открывающая сочинение, носит сумрачный и печальный характер. Звучание аккордов вызывает аналогию с перезвоном колоколов, сопровождающим траурное шествие.

В работе над этим прелюдом пианисту необходимо обратить внимание на строго одновременное взятие всех звуков, составляющих аккорды, так как даже малейшее их арпеджирование может уничтожить силу воздействия музыкального образа этого произведения.

Автору данной статьи и ее студентами-пианистам АМТИИ довелось неоднократно включать эти сочинения в свои концертные программы. Исполнение этих тонких миниатюр всегда тепло воспринимались как профессионалами, так и любителями музыки. 


\section{Выводы исследования и перспективы дальнейших разработок.}

Прелюдии для фортепиано А.Стырчи, Г.Няги, В.Ротару, С. Лунгула, К. Руснака, М. Стырчи, В. Сечкина, отличающиеся оригинальностью музыкального языка, ярким тематизмом, импровизационностью изложения музыкального материала, существенно обогатили национальный пианистический репертуар, вошли в золотой фонд фортепианной музыки композиторов Республики Молдова. В то же время, данные пьесы явились ярким вкладом отечественных авторов в развитие жанра прелюдии в мировой фортепианной литературе в целом.

\section{ЛИТЕРАТУРА}

Березовикова, Т. (1982). Константин Руснак. Молодые композиторы Советской Молдавии, Г. Пирогова (сост.), с. 74-85. Кишинев: Литература артистикэ (Berezovikova, T. (1982). Constantin Rusnac. In G. Pirogova (Ed.), Young Composers of the Soviet Moldavia (pp. 74-85). Chisinau: Literatura artistike).

Бирюков, С. (1984). Обаяние импровизации (традиции и современная советская музыка). Музыкальный современник (вып. 5), В. Задерацкий и др. (ред.)., с. 134150. Москва: Советский композитор (Biryukov, S. (1984). The Charm of Improvisation (Traditions and Contemporary Soviet Music). In V. Zaderatsky et al. (Eds.), M usical Contemporary (vol. 5) (pp. 134-150). M oscow: Sovetskij kompozitor).

Гупалова, Е. (2008). Отечественный пианистический репертуар в Республике Молдова (автореф. дис. ... канд. иск.). Кишинев (Gupalova, Е. (2008). Autochthonous piano repertoire in the Republic of M oldova (PhD thesis abstract). Chisinau).

Клетинич, Е. (1983). Инструментальная музыка Георгия Няги. Композиторы союзных республик (вып. 4), М. Нестьева (ред.-сост.), с. 3-33. Москва: Музыка (Kletinich, Е. (1983). Instrumental music by Gheorghe Neaga. In M. Nestieva (Ed.), Composers of the Soviet republics (vol. 4) (pp. 3- 33). Moscow: M uzyka).

Коваленко, С., Левинзон, В. (сост.) (1988). Произведения для фортепиано. Кишинев: Литература артистикэ (Kovalenko, S., Levinzon, V. (Eds.) (1988). Pieces for piano. Chisinau: Literatura artistike).

Мирошников, А. (1973). Фортепианные произведения молдавских композиторов. Кишинев: Штиинца (M iroshnikov, A. (1973). Piano pieces by Moldavian composers. Chisinau: Shtiintsa).

Сечкин, В. (2014). Пять прелюдов-картин для фортепиано. Кишинев: Pontos (Sechkin, V. (2014). Five preludes for piano. Chisinau: Pontos).

\section{АНОТАЦІЯ}

Хатіпова Інна. Прелюдії для фортепіано композиторів Республіки Молдова в репертуарі студентів-піаністів Академії музики, театру та образотворчого мистецтва.

Автор статmі звертається до жанру прелюдії - одному з найбільш поширеного у фортепіанній музиці. Жанр прелюдії знайшов широке розповсюдження у творчості композиторів Республіки Молдова. Метою статmі є розгляд прелюдій для фортепіано, що були створені вітчизняними авторами та внесені до педагогічного репертуару студентів-піаністів кафедри спеціального фортепіано Академії музики, театру та образотворчого мистечтва, з виконавської точки зору. Автор аналізує форму цих творів, риси стилю, особливості драматургії, 
композиторську мову. Стаття містить численні виконавські та педагогічні рекомендації для молодих піаністів. Автор робить висновок про роль даних п'єс в оптимізації прочесу професійної освіти та виховання студентів.

Ключові слова: фортепіанна музика, жанр прелюдії, музична фрорма, фортепіанна фрактура, молдавський фольклор, виконавський аналіз, концертнопедагогічний репертуар, композитори Республіки Молдова.

\section{SUMMARY}

Hatipova Inna. Piano preludes of M oldovan composers in repertoire of the student at the Academy of M usic, Theatre and Fine Arts.

In the present article the author presents a review of piano preludes written by Moldovan composers in the second half of 20th century which are frequently studied at the Academy of M usic, Theatre and Fine Arts of the Republic of M oldova. The author seeks to characterize their imagery, musical language means and technical difficulties that can be encountered by young performers. The works analyzed are approved in the author's teaching practice.

The preludes were written by Gheorghe Neaga, Vladimir Rotaru, Semion Lungul, Constantin Rusnac, Alexei and Marian Stârcea, Vitaly Sechkin. Some information about these miniatures can be found in research by musicologists E. Kletinich, A. M iroshnikova, E. Gupalova. A detailed analysis from a performer's standpoint presented in the article is made for the first time.

The piano pieces indicated above are diverse. The two preludes by A. Stârcea contrast with one another: one has a lyrical character, whereas the other one differs in its drama and flustered character. The piece by $G$. Neaga bears the traces of impressionist music. C. Rusnac's and V. Rotaru's creations are composed using Moldovan doina stylistics, and S. Lungul's lyrical miniature is nationally neutral. In the two preludes by M. Stârcea, modern musical language means are used, and sharp rhythms and dissonant harmonies abound.

The article also presents five preludes-pictures by Vitaly Sechkin, a Ukrainian composer who spent his last period of life in Moldova. Inspired by Moldovan vivid landscapes, they differ in their imagery and tempo. Nonetheless, each of the miniatures has its own individual appearance and peculiarities of style.

All the works reviewed are distinguished by bright themes and original music language. They represent a substantial enrichment of national piano repertoire and are a striking contribution of autochthonous authors to the development of the prelude genre in the world's piano music.

Key words piano music, prelude genre, musical form, piano texture, Moldovan folklore, performing analysis, concert and pedagogical repertoire, composers from the Republic of Moldova. 